\title{
Creative Craft and Design Microenterprise in the Age of Social Media
}

Q: More people, younger people, [seem to be] setting up their own businesses these days than there was in my generation, Gen X. Do you have any sense of why that might be the case?

A: A couple of things come to mind and one of them is, I wonder how important the role of the internet is to that, because [...] you can reach your customers quite directly, which maybe you wouldn't have had the opportunity to do not that long ago. You would have had to fulfil large orders or work for somebody. And there's quite a broad range of things, businesses, that my friends are running themselves, from fitness to art classes, to doing tourism, and a number of different areas. But yeah, I wonder if the access to the internet and access to the people [...] to your customers [is the game changer]. (Corner Block Studio, picture frames, emerging maker, November 2015)

In the new millennia, in most if not all sectors of the economy, markets have become increasingly globalised, disrupted and competitive. Not only has technology enabled advances in the means of production, but in the craft and design sector, as elsewhere, it has also given rise to changes to traditional distribution models, with the result that physical shopfronts and product shelf space are being usurped by or coupled with online retail options. However, the ease of establishing online shopfronts today hides the complex work required to start and run a small business, especially one operating in an increasingly competitive global space with isolated

(C) The Author(s) 2020

207

S. Luckman, J. Andrew, Craftspeople and Designer Makers in the

Contemporary Creative Economy, Creative Working Lives, https://doi.org/10.1007/978-3-030-44979-7_8 
producers and narrow profit margins. All this raises new challenges for craftspeople and designer makers, who, to operate successfully as a microenterprise in this emerging global market, require not only practice-based skills but also business knowledge and entrepreneurial talent sets. A creative micro-economy that emphasises 'long tail' buying (Anderson 2007) 'directly' from the maker offers both creative graduates and more established designer makers micro-entrepreneurial pathways not previously open to them. To realise the potential of these opportunities, skills in professional practice need to be complemented by competencies in other areas, particularly the use of social media as a marketing tool, which requires the promotion of producer self-identity (including the maker's home and family relationships) as part of the value being sold (Luckman 2015).

In this chapter we report upon how makers experience and negotiate the increasing demands of social media. In particular, the highly visual and stylised world of photography-centred social media such as Instagram that emerged in this research as the dominant platform in this highly aestheticised marketplace. Even with the ongoing popularity of physical markets (as discussed in Chap. 6), maintaining an online professional identity is now a core part of the work involved in being a contemporary maker. But although the ease of establishing an online retail presence was a recurring theme, the work involved in maintaining and building their brand profile was identified as the real challenge by interview respondents (Fig. 8.1). Most found it relatively easy to set up their own website and even professional social media presence in this new and increasingly crowded market, but the challenge and time commitment was in developing and maintaining an online presence that meant they stood out from the crowd. In this way, the demands of social media as a new normal baseline are a new administrative burden facing the self-employed and creative microenterprises in Australia's making community.

Social media has been a game changer for craftspeople and designer makers, albeit one very much linked with the experience of negotiating work-life relationships. There are two main reasons for this. Firstly, the simple reality is that, even for people with making spaces outside their place of residence, all makers spend at least some time engaging with their online worlds beyond their formal studio making time (often as frequently noted by our interview respondents: 'in the evenings, after the kids have gone to bed'). Secondly, as we know, the identity of the maker as an identifiable individual with a story is key to the way the handmade is positioned in the market. The lines around what and how much of one's self 


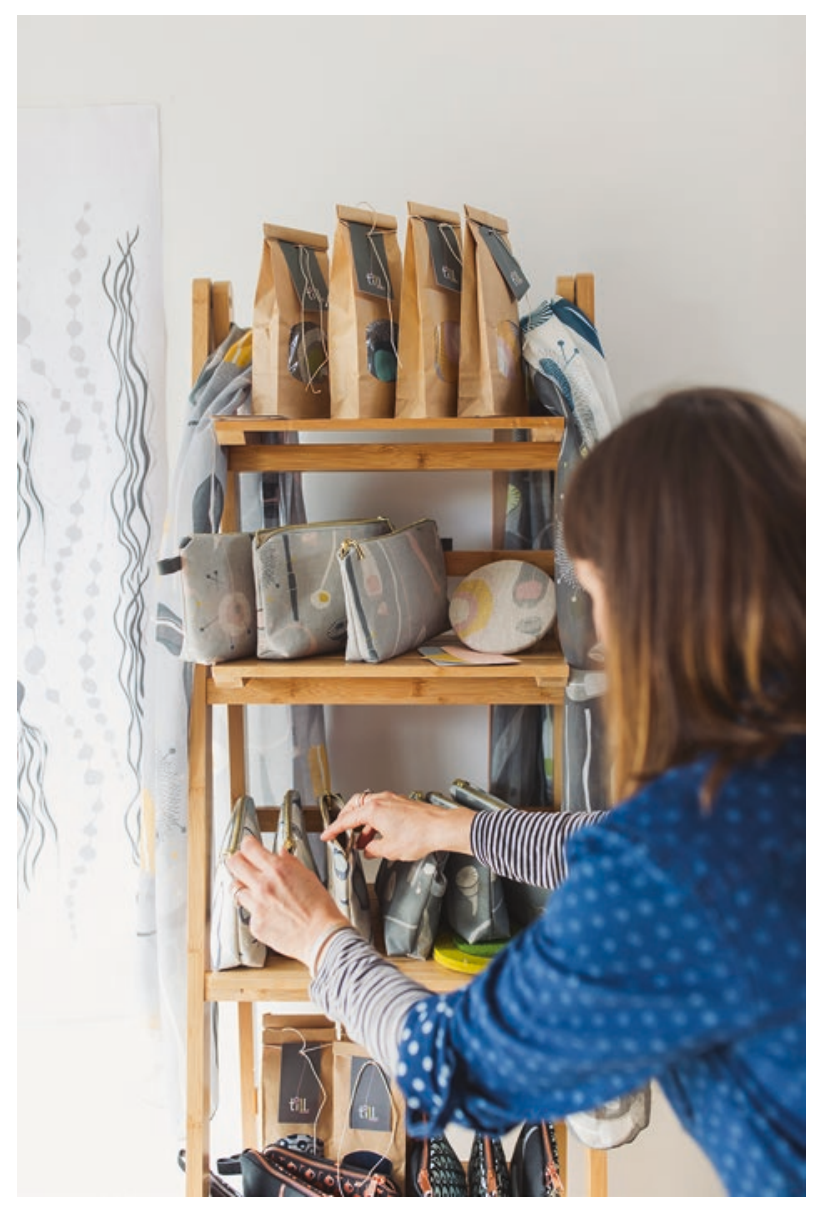

Fig. 8.1 Phillipa Julien, Till Designs (http://www.tilldesigns.com.au/), arranging products for sale. (Photograph: Rosina Possingham Photography)

to show, and how, are thus are central questions makers need to negotiate as they position themselves, especially online. For craftspeople and designer makers, entrepreneurial labour, as it is for other parts of the cultural or creative industries, 'is intertwined with' one's work identity (Neff et al. $2005,308)$. This includes mobilising for sales purposes 'the instrumentality of affective relationships' enabled by social media (Duffy 2016, 443). 


\section{The Online Worlds of Australia’s Craftspeople and Designer Makers}

Many of the current makers we spoke with still recall the pre-internet craft marketplace as a place where professional practice-based associations (not commercial operators) ran 'professional' craft fairs where stalls were run by, among others, potters, glass artists, jewellers, instrument makers and textile artists, all of whom handed their goods over to the purchaser wrapped in newspaper. In this still relatively recent past, branding was taken care of with a business card and, if one had a computer, a rudimentary website. In today's era of self-commodification, image is everything, and for creative workers self-branding is essential (Hearn 2008). It is expected that makers will have a social media presence on multiple platforms, alongside a professional-looking website, which adds a layer of complexity and demand to the time creative entrepreneurs need to spend working on the non-creative side of their business, above and beyond the actual work of making. It is not surprising, therefore, that the vast majority of our interviewees reported spending a significant number of hours creating and maintaining a professional and engaging online presence, as well as building and sustaining the networks that make these sites useful and viable promotional tools. Beyond the presentation of a branded self, social media were also seen as important in cultivating a connection with the processes of making itself, by providing some of the story behind the work as well as the making individual:

I feel like what I've been trying to specifically show is, I don't know what the specific word for it is, but like [cultivating] friendliness and the involvement of customers. So I've found through social media [I can describe] the different processes, sort of giving them a bit of an insight into something that is not known to a lot of people. Glass blowing is just this magical thing, a lot of people don't even know where it begins. So I've been trying to sort of show on my Instagram and Facebook little bits and processes and I feel like that gives a bit more of a connection to my work and also to me. Because I don't want to just sell my work off, I want people to interact with me as well. And I feel like especially with the Helpmann thing, for the VIP opening night, I chatted to so many different people and they were so fascinated 
in my work, but also in me. So I think because I'm so connected with my work, I'm sort of selling a part of myself and my personality with it. So I think that connection is important. (Emma Young, studio glass blowing, emerging maker, March 2016)

Almost all participants felt there was room for improvement (especially in turning 'likes' and page views into sales), but on the whole they considered they were pretty adept at or at least familiar with using social media to tell a story about themselves and had cultivated the aesthetic, discursive and digital capabilities required to present the kind of personal statements that are becoming increasingly generic in this space.

The growing connection of craft and design to arts training in higher education is significant in this process of establishing a storyline, given the longer history of artists' statements in the visual arts as an established profiling genre. With crafts and design increasingly being taught in universities as part of fine arts degrees (Banks and Oakley 2016; Luckman 2020), the need to be able to write an artist statement-to articulate a sense of self and a vision to accompany the practice/work-is an increasingly normalised part of the craft and design curriculum, far more than it would ever be in a more vocationally oriented training context. This, coupled with students' own increasingly lifelong experiences of presenting themselves online as well as their knowledge through online immersion of the verbal and visual aesthetic codes of their fields, means the standards for self-presentation not only possible but demanded today are far higher than they were even a decade ago.

For the reasons above, the need to engage on social media as makers was taken as a given by most of the people we interviewed for this project. Indeed, a number of people we spoke with identified the capacity to control how others see them and their work from a relative distance as a major boon for a sector that demands self-promotion but attracts large numbers of women and/or creative introverts:

I think some people can struggle with that [directly experiencing customer feedback on their work at markets]. I think social media can be good in a way because that can actually give you a little bit of separation from it [because] I think it can be challenging for people who are new to actually promoting your work face-to-face with people; [it] can be really challenging that you're actually selling your work and standing by it and discussing it, rather than having had the time to actually prepare something beforehand 
and put that on your website or take photos and show it and be totally in control of that situation. You are actually projected out there, aren't you, and that can be daunting. Particularly when you're highly invested in something that you've actually made. So in many ways, social media is a much less confronting way of presenting it, a sense of self and your relationship to your work, than the traditional standing next to your product at a stall at a market or doing the fair circuit. (Jane Barwick, Bowerbird Design Market, June 2016)

But with work-life negotiations being problematised by social media, interviewees also frequently commented on the need to make decisions about how much to share. Negotiating this presented challenges, especially in social media worlds where people had existing personal accounts:

I have a work [Facebook account, a] private one and a work one. You have to, I think. You've got to set up your private and then from your private you set up a business, is how it works and it's good because then you just keep it really business and whatever's related to your business on the business. It gives a good definition. (Till Designs, textile design, emerging maker, February 2017)

Q: So social media is big for you?

A: Yes, absolutely.

Q: Is that in terms of marketing or direct sales?

A: More from a marketing perspective, but it really helps to attract people into the space and also, if I've got other projects on, that is really essential. So I had a crowdfunding campaign actually to launch a new product before I moved into the shop. Partially obviously to fund the first print order but also to attract people back into the space, so as a reward I gave ten percent off of all store-wide in my Brickand Mortar shop to all backers who purchased something through the pre-order system, so that worked really well for me and Instagram helped a lot in getting people onto that page and making pledges.

Q: Does that present challenges, has it been sort of difficult to figure out how to present a sense of yourself as a professional maker and person but also keep something separate?

A: Not so much, I just try to filter everything through my "would I show this to my mother, past teachers etc.", kind of a filter and that works quite well. (Illustrator, emerging maker, September 2015) 
The reference to the 'would I want my mum to see this' test in some ways captures the wider maturation of social media use that occurred across the timeframe of the research project (2015-2018), as well its acceptance as a cross-promotional marketing tool. As a space where the boundary between work and private identity may seemingly and often does blur, the rules of how this is done are settling into place somewhat. Many people no longer considered it taboo or undesirable to display their non-work self publicly. Indeed, in a contemporary take on the family photo strategically positioned on the office desk, in many cases the opposite is also true as part of self-branding and professional relationshipbuilding (Humphreys and Wilken2015). The question thus becomes: In a multitude of professional contexts where these boundaries are becoming blurred, which representations are not only acceptable but perhaps desirable to project? The world of creative employment has long demanded of its workers particular performances of self. Today, a market intent on buying as direct from the hand of the maker as possible clearly is ripe for successful uptake on social media, but it also demands the performance of an ideal maker self as part of identity work-as a continual process of becoming (Taylor and Littleton 2016, 17). We will return to this discussion later in this chapter. But first, we need to map out in a little more detail how the affordances of different social media fit into the business practices of Australia's contemporary craftspeople and designer makers.

\section{The Rise and Rise of the Visual: Instagram}

[I have] just over 1000 Instagram followers at the moment. [...] I don't really get a lot of business through Etsy direct, but Instagram I get about 98 per cent of my [sales] through Instagram. (Handmade toys, established maker, October 2017)

I'd be lost without Instagram. (Simone Deckers, textiles, established maker, March 2017)

Very early in this project the popularity and value of Instagram for Australian makers over websites such as Etsy emerged as one of the standout research findings:

I don't like Etsy, I find it very difficult to navigate and pot luck if someone finds your work. I think you have more success through Instagram because 
you're picking your audience and it's finding you as your right audience, and then [have a] website [you direct people to for] your sales. (Kate Evans, textiles, established maker, October 2017)

In this stylised, aestheticised and design-oriented marketplace, Instagram as a visually focused platform is proving successful even as a generator of sales, especially for those whose work lends itself to presentation in aspirational interiors or modelled settings:

[It] seems to be the hot thing at the moment. The ability to expose your work to a large number of people who are-I mean, it's visual work obviously, so to be able to promote it through a medium which is all about [the] visual is really good.[... it's] very important to fill in some of the story behind [the product]. I think those things are, I realise the importance of that. So posting a picture now, I'll always [provide] details about the piece, or hint at the back story, or something like that. (Scott van Tuil, furniture maker and designer, emerging maker, February 2016)

Why do I love Instagram-because it's quick and easy and it's not bitchy like Facebook. You haven't got all that political stuff and the personal politics and it's just-from the people I'm coming across anyway-it's just photo sharing, and I'm connecting with lots of other artists and Spoonflower people that I used to-we used to follow each other on Spoonflower, but because I don't really do it anymore, they probably think, "Oh, well, she's stopped doing it." And now suddenly we're all finding each other on Instagram. So, I like that about it. (Robyn ('Boo') McLean, Bippidii Boppidii, textile design accessories and homewares, established maker, July 2017)

For those makers with a skill set that incorporates styling and photography capabilities alongside making, this aspirational styling in many ways forms a significant part of value of the product being sold:

A: We're so active on Instagram. We get a lot of followers from Instagram coming to us and saying, sort of giving us feedback through that which is amazing and most of our orders are actually Instagram followers. $[\ldots]$

Q: Do you think having the design business and the design sensibility [of] interior design helps you there? 
A: Absolutely. I'm trying not to cross those two businesses to much. So I have one account for my styling and one account for this. So I'm not sort of trying to show that I'm the two people, but I definitely find that if you have nice photos and style the photos it will definitely bring in more people. People want to see beautiful stuff. [ ... ] We get, I would say 90 per cent of our business coming from Instagram and that's actually only Instagram. We don't have Facebook. [...] The commissions find us through Instagram as well. [...] We have committed to Instagram for being our only sort of source. We haven't, we decided against Facebook because it feels like it's a, it's dying off a little bit especially for businesses, but Instagram is constantly updated, so easy to use and it's funny because [there's] some really big businesses out there that don't have many followers on Instagram so they must have caught their people from somewhere else. But it's such a new thing and it works really well. (Beatrice Fagerström, woodworker, emerging maker, October 2015)

Consequently, while most makers persisted with Facebook accounts (see Fig. 8.2), often as legacy accounts now focused largely on private use rather than business marketing and sales, Instagram was the platform our respondents preferred for promoting their work. It was also the one with the strongest ongoing growth and take-up among the making community across the four years of the project (Fig. 8.3).

The reasons for this were multiple, but ultimately most came down to ease of use and reward for effort. Simply uploading a photo was seen as less onerous than drafting promotional or descriptive text; adding some text on Instagram is possible but, importantly, not mandatory. Instagram was thus considered the doable way to engage in social media posting regularly without it being overly burdensome, especially for anyone who was constantly making and had new content to show. Even if this was not the case, images could be banked up for a more staged release:

Instagram['s] easy to update things, you just, every day take a photo or save up 10 photos for 10 days, publish one each day, and then you keep having new people look at your profile. Not potentially buying [...], but at least you get people looking. (Tian You, ceramics, emerging maker, October 2016)

Thus, the capacity to post something quickly, with minimal need to interrupt their making or other work, was key to this platform's value: 
Social Media (\%)

120

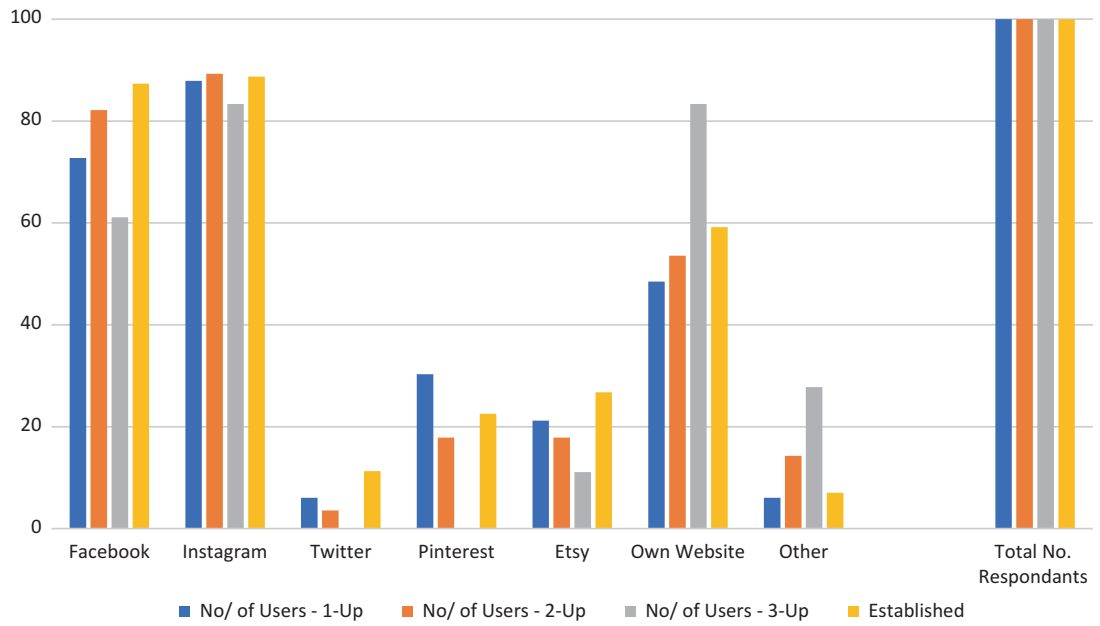

Fig. 8.2 Online sites through which emerging and established makers were actively marketing/self-promoting themselves. Note: 1-Up, 2-Up and 3-Up refer to Years 1,2 and 3 of the emerging maker interviews

[I like Instagram's] immediacy I think, because I can be sitting in the studio and making something and take a photo, and it's posted, and it doesn't have to be a really big effort. I mean website maintenance takes a lot of effort and time. Facebook, well the fact that you can link Instagram and Facebook is really good. I think Instagram is great because it's image driven, so you don't necessarily have to say anything. (Tanja Von Behrens, jewellery, established maker, February 2016)

Hashtags were another quick and useful way of connecting with new audiences, something much harder to achieve on Etsy and Facebook:

It [Facebook] is helpful to have there almost the same as I would say of the online shop, but it's not really the avenue where new people are finding my work; Instagram is something where it's very easy to discover new creatives, new accounts. Facebook is not driving any new customers to me, it's just something where I've got that link there on my website and if people want to use it they can. $[\ldots]$ The Facebook account I [...] set it up while I was 


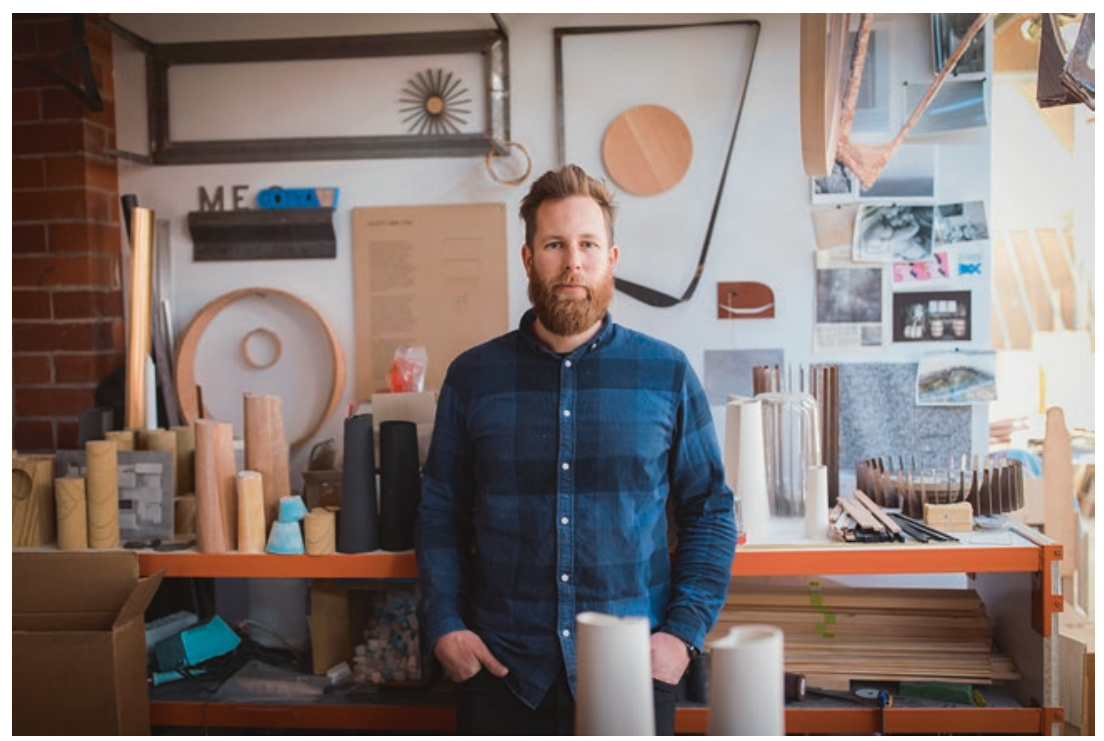

Fig. 8.3 Scott van Tuil (http://www.scottvantuil.com/) in his studio. (Photograph: Rosina Possingham Photography)

still at uni $[\ldots]$ and then actually really honed it after I left, but over so many years it's gained almost five hundred followers at the moment, but Instagram I've been using for one year and that already has overtaken the Facebook page by many times. So just the effort to get anyone on Facebook is [far greater.] People are discovering - I'll be at a market stall and the last [time] I was at Finder's Keeper's I think at least five people happened to mention to me, "I found you on Instagram". (Illustrator, emerging maker, September 2016)

The hashtags help in terms of people finding you that haven't seen you before. So it's quite, quite a good way, I'm surprised because I'm not really that keen on social media [...] I find that Instagram is working a lot better for me [than Facebook] it's just quite visual and I actually do enjoy it. (Ulrica Trulsson, ceramics, established maker, August 2018)

[With] Facebook I find [it] really hard to get out of just your friends because I think you need a lot of people to come and see your business cards and stuff to like it or be friends when you're "Hey guys I've got a page, come like it" on your normal Facebook profile. But whereas, Instagram, because 
you use hashtags and stuff people can find you by looking for that hashtag, so I find it a lot more easier to get, for people to find you. [...] Yeah [it's] broader, randoms can find you so much easier and it's visual as well. (Tara Matthews, illustrator, emerging maker, August 2015)

As is evident in these interview extracts, Facebook is not quite dead yet. Though it was far less of a focus for most of the makers we spoke with, and no longer at the heart of many makers' business communication plans. Initially it was commonplace for makers using Instagram to automatically link it to their Facebook account to enable easy cross-posting, but as always, the best platform is all about reaching the right market. If the client base is more accustomed to Facebook and less likely to be active on Instagram, the former remains a solid promotional option:

Well I know you're supposed to use them separately, but at the moment I'm just doing it on Instagram and sending it to Facebook as well. But I get a lot, we get a lot more response on Facebook. I think it's because our client base is a lot, is generally, probably 40-plus mostly. (Small and Pickering, metal sculptures, established makers, May 2016)

Twitter barely featured in our study. In the Australian context, it is considered a largely text-based forum more attuned to the needs of the white-collar work culture. A clear loser here was the similarly visually focused Pinterest, which for our respondents had been effectively superseded by Instagram, to the point that by the third year of the emerging maker interviews, not a single respondent identified as having an active account (see Fig. 8.2).

\section{Social Media and the Labour of Maintaining an Online Presence}

As we have just seen, the way in which Instagram is perceived to make regular and potentially far-reaching social media posting relatively easy when compared to other platforms and online communication modes is central to its attraction to large sections of the Australian craft and designer maker community. The significance of this becomes clearer when we drill down into the findings about how easy or hard respondents found marketing their work generally and keeping up with social media in particular. Almost everyone remarked on how much time and effort marketing (especially online) takes and said that there must be better ways to do it (see 


\section{Marketing (\%)}

60

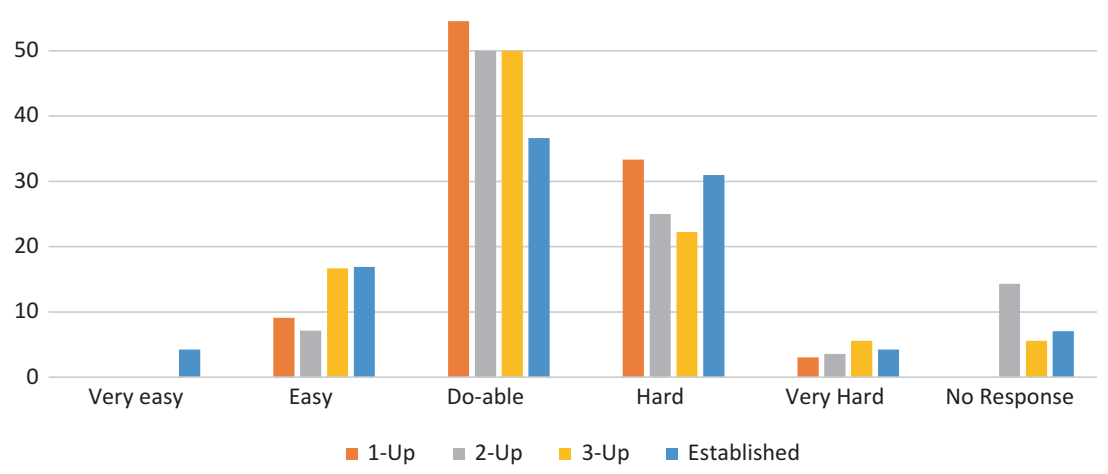

Fig. 8.4 Ease of marketing the business. Note: 1-Up, 2-Up and 3-Up refer to Years 1, 2 and 3 of the emerging maker interviews

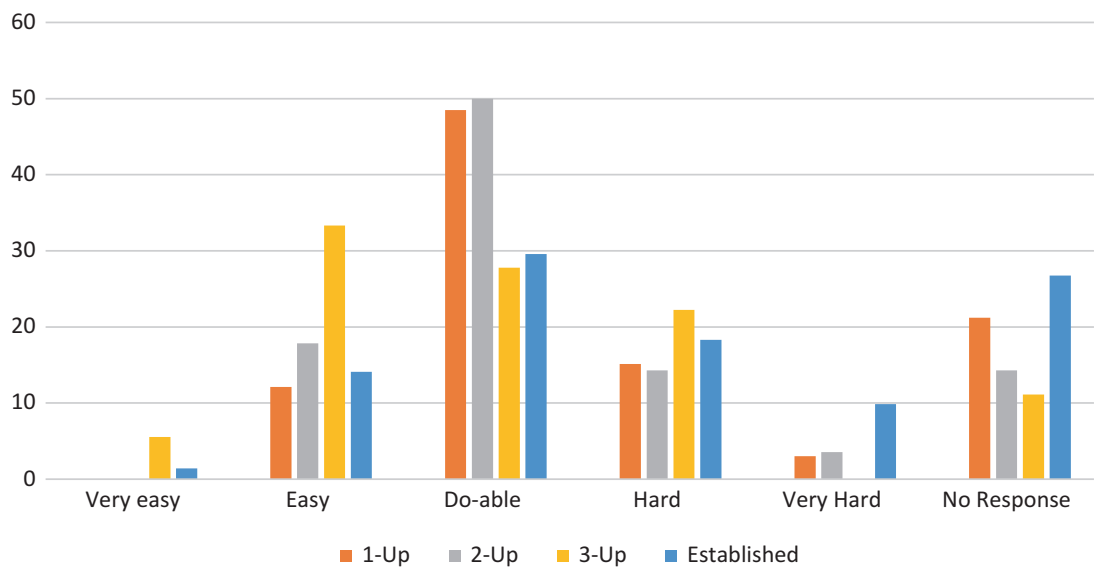

Fig. 8.5 Ease of updating the online shop. Note: 1-Up, 2-Up and 3-Up refer to Years 1, 2 and 3 of the emerging maker interviews

Figs.8.4 and 8.5). They sought such information and guidance through searching the web, networking with other makers and membership of professional associations. The centrality of the visual to Instagram's popularity means that desired guidance included information on a broad range of proficiencies, including producing quality photographs: 
I realise my photography is somewhat lame and it could be better and so I'm in the process of now remaking a lot of my work specifically to take good photos of it. [...] So that I can take really nice manicured photos, really styled photos and put them on Etsy and my own website. (Julie Frahm, lampworking/glass beads, established maker, May 2016)

Notably, across the board, in this project the main areas in which makers consisted reported wanting more support and training were marketing generally and social media marketing in particular.

\section{Managing Social Media}

By far the greatest burden makers felt marketing placed on them was the time involved, not only in regularly updating their own websites and accounts but also in responding to feedback and comments on previous posts and the addressing the networking obligation to reciprocate: to go out and 'like' or, preferably, comment upon others people's work in the community. We asked participants how much time they would spend each week updating their sites, 'liking' others' posts and similar networking activities:

I hate to start them [online accounts] and not invest time in them [...] they normally do take time. And Instagram, I don't think-well I said sort of 3 hours [as the amount of time a week I spend on this], it could do with more, and I will start giving it more time and more forward planning. And also because it's two-way, you're getting feedback back from people or comments, and I want to respond to those and keep up with them-which is an enjoyable part of it, it's connecting with people, it's really great. But it also, it's kind of like your inbox can get full of emails and it's not because you don't want to respond to them, it's just that you've got plenty on. (Corner Block Studio, picture frames, emerging maker, November 2015)

Oh it's, a lot, a lot and it's just styling and everything. That can take, that takes hours because, just getting the light right and getting all the setups and everything. So probably 10, 15 hours a week on Instagram if you combine that with the styling and everything and editing the photos. (Beatrice Fagerström, woodworker, emerging maker, October 2015)

They're [the Facebook and Instagram accounts] actually taking up a huge amount of time and especially because having images of your work is so important and I want to teach myself how to do that. So it might take me 
an hour to take a decent photo and edit it and that kind of thing. But I think that's a really important part of making sure that I'm sustainable I suppose. (Laurence Coffrant, jewellery, emerging maker, January 2016)

Consequently, the makers we spoke to employed a number of tactics to try to keep on top of the work demands of social media. As we saw, the Instagram-to-Facebook combination was a common one for makers, effectively enabling them to post to two different platforms simultaneously. Some other makers sought to set aside a circumscribed amount of time each week to plan and prepare their social media:

So at the moment I'm hoping to have one day a week where I go through and choose things to go on there, or plan it for the rest of the week. I probably, I post a lot more to my Instagram but that's probably when and where things are happening, not so much advertising, or talking about different aspects of my practice. So I'm trying to work out at the moment whether I want to have the two separate Instagrams or just one, because I post a lot of what I do on my personal thing is kind of, there's an overlap. So just trying to work that out. (Cara Pearson, studio glass blowing, emerging maker, February 2017)

As these comments reveal, especially towards the end of the project, as the dust was beginning to set on the mid-2010s hype around Etsy and social media more generally, there was a growing tendency for makers to pick one or two platforms on which to focus and to prioritise doing these well rather than covering all online media to their mind badly. Similarly, we observed the emergence of greater differentiation between the platforms, with some being used to curate a record of collected works, while others were more focused on selling. Likewise, there was a greater emphasis on setting up accounts just for business purposes and thus having a clear demarcation between personal pages and business pages. In some ways this was a side effect of the decline of Facebook for professional purposes, given it is a more established platform and one with greater capacity to blur the boundary between the private and professional self (for both tech-related and, mostly, historical context reasons). In the final year of interviews, the idea that social media could or should be outsourced to specialists, just as taxation often is, began to emerge as a strong theme. One or two makers were already doing so; others aspired to. In this way, 
even the 'branded self' (Hearn 2008) is now simply the kind of marketing work that can be outsourced.

This is notable, too, for how it connects with wider social trends around attitudes to social media and the way it has settled into our everyday lives. Certainly the period of the project coincided with growing mainstream critique of social media and a mounting discontent with its impact on people's wellbeing across much of the Global North, if not beyond. Facebook, in particular, had been coming under increasing high-profile attack over a range of concerns around privacy, hacking and undue political influence (including possible fraudulent behaviour with the potential to manipulate national electoral outcomes). As a result, many people, including some that we spoke to, are stepping back or downshifting their personal engagement with social media, focusing on them as promotional/professional tools:

I have two Instagrams, one was sort of for private life and one was for [the business] — and that got too hard to handle [...] Now I'm just a bit more choosy about what I put on there in relation to myself. (Gabbee Stolp, jewellery, emerging maker, March 2018)

In this context, Instagram (like other, newer social media) has benefitted from people learning from their earlier experience of Facebook and setting up subsequent accounts that were either work or personal-generally the former-with a more targeted purpose and thus potentially greater longevity:

I'm on Facebook but really the only reason I'm on Facebook is to spruik my wares otherwise I wouldn't be on it. Same with Instagram, I'm in Instagram too, but only for that reason. (Minna Graham, ceramics, established maker, July 2017)

Facebook I have my own, so business account and personal. Instagram I don't have a personal account, it's all business and I just talk about business things on my Instagram page. (One Happy Leaf, jeweller, established maker, November 2016)

Without wishing to essentialise around age and digital proficiencies, there were also some notable generational differences in attitudes to social media and online sales generally and their cost benefits: 
And I feel actually like I'm at a point with the whole social media and selling online thing where I'm just letting everything simmer a bit and working out what the hell I'm doing with it. Because I do find it a challenge, I don't want to spend my time doing that, it actually doesn't interest me at all. I'd rather be in my studio working. I find it really amazing that a couple of ceramic artists that I know appear to sell a lot of work online and I just think, 'I don't know how you do it,' it takes so much time. I mean even if you're producing that repetitive item so you only have to shoot it once and it's there in your shop and you've just got to keep the inventory up to date or whatever, you have then got to pack it, and you've got to drive to the post office and post it. And if it's ceramics and it's a big platter that's a lot of packing. In my opinion, that's hard work. [ ... ] And I just think I don't want to do that, I'd rather be making. [...] I have been bought up, see, with my parents' model, they have no social media, they have no website, they've never done that. They have outlets and those outlets send them orders, they basically work to orders you know, and I love that. [...] With some of the younger people I sense it's [selling and promoting online] busy work, it makes them think they're getting out there when you're not really. (Ceramics, established maker, November 2015)

I can only manage Facebook, it's that one thing I, I do. I would like to be on Instagram but I just don't have the time. It may come in the future, but also I find I have a slightly addictive personality and I just go down a tunnel. And I could waste an hour and I don't have an hour to waste, so I have to be incredibly disciplined so I think if I took on more social media, it wouldn't be good for my practice. (Vicki Mason, jewellery, established maker, April 2016)

On the whole, more established and/or middle-aged or older makers were more likely to report finding marketing and other social mediarelated tasks harder, if only in terms of the time burden, which they were more likely to factor into their personal accounting of the value of committing to this kind of labour. In comparison, emerging makers were far more likely than established makers to report finding marketing 'doable', but on the whole they nonetheless did not have the web traffic, sales or profile of those who found this aspect of their practice more difficult.

Thus, a concerning early tendency, especially among the emerging makers we interviewed, was the false security that having an online business identity brings. Maintaining social media profiles can take up much of the time makers have to give to their business each week. Especially for so-called digital natives, the simplicity of creating online professional 
profiles-particularly across multiple social media (one's own website as well as retail website platforms) - appears to be masking the real challenges of building a reputation or brand that converts to sales and not just likes. Emerging designer maker Joslin Koolen captured the cultural nuances in play beautifully in our discussions with her:

A lot of people [are] on Instagram, some people are very active on Instagram and it's a great medium. But to be honest it's very visual and I think people like what you do but it doesn't necessarily mean they're going to follow through and buy it. I think that's what people have to understand is when someone likes you and they follow you they may just enjoy looking at your work, that in itself to a lot of younger people is ownership, so they don't feel they need to then go and buy it. A lot will try and create a similar feel within their home or in their workspace. [...] it's just an extension of Pinterest, really, and I think a lot of people when they go into business forget. (Joslin Koolen, metalwares designer maker, emerging maker, January 2016)

Oh, look, I think it's just like a picture book. People acquire images. [ ... ] I think if you really want to sell through social media your whole campaign has to be focused on just selling through social media because it is a massive world. I know that I've definitely raised my profile and that people have recognised my work and I probably have had some work through it directly or indirectly. [ ... ] Initially I took it really personally if people didn't like my stuff but it's all about whether other, if other people like it or, and you have to be constantly in people's faces. I find that blogs have the best followers on Instagram because they're constantly adding information and people know that they don't have to, they're not obligated to buy anything or they're just trying to sell a product. I think it's very important that Instagram [posts] relate to people on a personal level but without getting too personal as well otherwise they see just you trying to sell something. [ ... ] I mean some people are heavily involved in Instagram and they're posting stuff daily. [...] People's attention spans aren't there anymore. They want instant gratification and they want something different all the time. [...] collecting the images is a form of ownership. (Emphasis added; Joslin Koolen, metalwares designer maker, emerging maker, April 2017)

Successful creative self-employment is clearly more than a case of 'build it (online) and they will come'. Indeed, rather than being a licence for instant success and profile, having an online professional identity-not just for makers but for workers across many creative professions-is now simply a taken-for-granted starting point, not an end point. It is a necessary 
default; it will not necessarily build reputation or sales. Existing online in a professional website proves simply that one exists and is contactable. Being 'Google-able' professionally is a new baseline, offering evidence of the reality and legitimacy of one's professional identity. It operates in tandem with, but not necessarily in addition to, one's offline presence.

A concern here then is that much social media activity undertaken by craftspeople and designer makers runs the risk of becoming a form of 'hope labour' (Kuehn and Corrigan 2013) whereby unpaid labour is undertaken 'in the present, often for experience or exposure, in the hope that future employment opportunities may follow' (Kuehn and Corrigan 2013 , 9), though without guarantee. Duffy (2015) calls it 'aspirational labor':

[A] form of (mostly) unpaid work, aspirational labor involves productive activities that (1) participants believe has the potential to pay off in terms of future social/economic capital; and (2) ensures that female content creators remain immersed in the public circulation of commodities. (60)

For this reason, building an online profile needs to be grounded in a larger business strategy that has a focus not just on to how build it, but on getting word of your presence into the right markets. Without a considered approach, the time-sink that is online promotions (and social media in particular) can become a form of micro-entrepreneurial 'busy work', providing the illusion of productive activity to no actual profitable end.

\section{Digital Technology and Creative Selling: A Boon AND A Curse}

In a wide gamut of fields, including certainly in the world of social mediabased microenterprise that features in the Australian craft and designer maker scene, individuals need to present to the market not only their professional skill set and relevant personal qualities but also a picture of themselves both figuratively and literally as socially embedded in non-work networks - families, personal partnerships and friendship. That is, they need to project themselves as having the kind of lifestyle potential customers or employers see as reflecting appropriate cultural capital:

Q: Do you have a story of yourself as a maker at all associated with that, or is it just the brand? 
A: Just the brand, that's the thing though from the creative courage thing, I need to get my story up on Etsy, so I really need to do more work on that because I don't have my story up there yet and that's, I know that's important as well. [...]

Q: Did Etsy in their programme give any advice on that at all?

A: Not specifically, they did sort of say in terms of your Instagram people like to see your lifestyle, they like to know a bit about you. And I kind of think, yeah that's kind of fair enough in a way. So $[\ldots]$ not specifically put a photo up of your kid, but about your lifestyle. So I do tend to, you know, if we go to the beach take a picture. The other day we were in the forest and I took a photo of that so I could give them an idea of where I live. But in terms of people in my life I'm not quite comfortable [putting them online]. (Sage and Peppa, ceramics, established maker, November 2015)

'Self-making' activities shared through social media normalise publicly marketing the maker through pictures of the home-based workspace and/ or their making as a family-friendly practice that is successfully integrated into the rhythms of the household (Fig. 8.6). Therefore, portraying a perfect balance between work and life becomes part of the online marketing performance and, by extension, what consumers hope to buy into. This 'networked identity work' (Vivienne and Burgess 2012) or 'selfmythologising' (Conor 2014, 7) requires the skills and capacity to present an idealised online self, one operating successfully in personal and professional contexts simultaneously. This brings with it all sorts of challenges around what to show, especially in terms of drawing lines between family and/or 'private' self and business:

[I don't have any reservations about how much of myself or my family to put online] in the written form, but that's something I am struggling with or just getting my head around with, because I've got my Instagram account and Facebook. I love Instagram, love it. So many beautiful sites on there. But you know do I show my kids' faces? It's really, I don't know if I'm paranoid or what it is, it's not even paranoid it's more that, do I want to share that I don't know. So the only photos of [my child] are of the top of her head and things now. But then I look at other people's and I'm like well they're not funny about it, so do I need to be funny about it? So that's something right now I'm figuring out what I'm comfortable with and what I'm not comfortable with. (Sage and Peppa, ceramics, established maker, November 2015) 


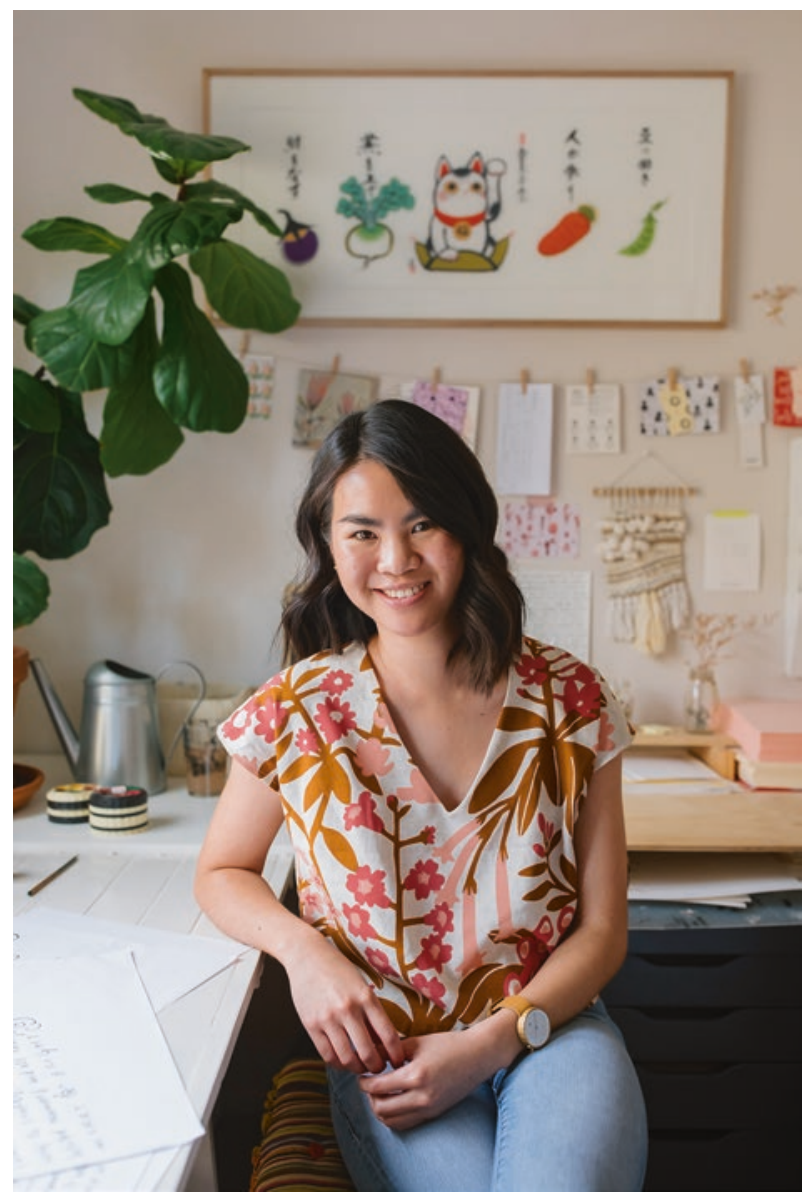

Fig. 8.6 Doris Chang, Little Sister Co. (https://www.doris-chang.com/) in her workspace. (Photograph: Rosina Possingham Photography)

There is a growing and important body of scholarly work emerging on the topic of women's use of social media as part of self-employment or small business self-promotion and the unique challenges women (and their families) face in this space (Duffy 2015, 2016, 2017; Duffy and 
Pruchniewska 2017; Ekinsmyth 2012, 2013; Mäkinen 2018; Naudin and Patel 2019). But in the new occupations social media is creating, new opportunities for women are also emerging. Notable here is the dominance of women in the still relatively new and emerging promotional occupation of 'influencer' that has itself largely emerged out of the visual, aestheticised world of Instagram. This field, too, is coming under increasing critique as it matures and grows, but it is useful to mention here, if only to situate the social media labour we encountered in this study within a maturing set of 'networked reputation' (Deuze 2007, 77) behaviours that do privilege some women (and men) and which increasingly are being codified into wider sets of professional, performative norms.

On the whole, what we found in our project was that the experience of promoting oneself online and being part of online communities, although sometimes difficult to translate into sales and certainly time-consuming, was a positive one. Indeed the way social media enabled the boundaries between selling a product, being linked into a community, marketing and simply liking and sharing to become blurred actually mitigated a lot of the fears makers may have held around marketing, especially direct face-toface pitches in market contexts. Arguably, it is the community-building or community participation aspect of this larger sense of self-promotion that mitigates some of the fears and reluctance this female-dominated group may have had around more flagrant or obvious self-promotional activity. There clearly are cultural factors behind this fear. As other scholars exploring gender and the promotional identities increasingly required of contemporary workers have written, 'self-promotion' has been seen as 'problematic for women because it violates female prescriptions to be helpful, supportive and other-oriented' (Moss-Racusin and Rudman $2010,187)$. Similarly, drawing more specifically upon research into creative workers, Taylor (2011) has shown that the selfishness demanded by creative working conflicts 'with long-established gendered positionings of women as other-oriented, attending to the needs of others and heeding their preferences' (367).

This book opened with references to the current moment as a 'third wave' of craft, a time when the zeitgeist favours the artisanal, craft and handmaking. Riding on the wave has been the figure of the hipster and with it a visual language deeply tied to artisanal making and aesthetics. The mainstreaming of this post-Etsy performative craft aesthetic has furnished craftspeople and designer makers with a shared visual and textual language from which to draw out their own personas. In a classic cycle in 
which previously niche activities become the mainstream, this aspect of running a craft is maturing and settling down in small and medium enterprises and sole trader businesses. Indeed, the enshrinement of particular performative codes as toolkit basics for a shared marketing aesthetic means that the challenge can now be to innovate, to stand out from the crowd, while still operating within a framework that provides sellers and buyers with a shared language of mutual understanding and a baseline for interaction and establishing maker belonging and credentials. But before seeming to end this discussion on too positive a note, it remains important to acknowledge that the aesthetic codes of the desirable artisanal persona are not equally available to all (Luckman 2015); rather, in many ways, this post-Etsy aesthetic has congealed into a new self-employed take on the more established workplace demand that creative organisations be "'hip" and informal' (Conor et al. 2015, 10). A yet further instance of the ways in which the labour market is being restructured whereby 'new resourcessuch as emotion and style or aesthetics - are being increasingly mobilized by workers and are productive of new hierarchies and divisions' (Adkins and Lury 1999, 610).

There is also a dissonance we have to acknowledge between the necessarily relentless positivity of craft and design marketing and self-promotion and the much more complex and often painful realities of maker's lives. Australia's craftspeople and designer makers, like creative workers more generally, are required to occlude 'all the affective features of cultural labour that do not involve affirmative feelings' (Gill and Pratt 2008, 15). This is simply 'part of the larger processes of governmentality in contemporary liberal democratic societies in which people have become selfgoverning subjects, disciplining themselves' to adhere to relevant norms (Taylor and Littleton 2016, 34). On a few, rare occasions, respondents, including some who are outwardly extremely successful, were willing to speak of not feeling included, accepted or legitimately part of the contemporary Australian craft and designer maker scene on account of being the wrong class (working, not middle), the wrong look (perceiving themselves as not photogenic or conventionally attractive) or otherwise an outsider. ${ }^{1}$ What we were not able to capture in this project were all those who had failed or chosen not to pursue this path, despite a desire to do so, as a result of their legitimate sense that this world was 'not for them'. Given the relative decline of many of the former sectoral gatekeepers, such as guilds and industry associations, and certainly the absence of any national body, the online environment becomes a self-imposed gatekeeper, leading 
to self-governing that conforms to its performative norms. ${ }^{2}$ The rise of social media aesthetic performativity, and the entrenching of putatively 'alternative' and progressive norms around the artisanal and handmaking community online, only serves (potentially) to reinforce these exclusions. This is something we know would be the last thing the makers we spoke to would ever wish to do, but something we all need to be attentive to as a community moving forward.

\section{Working Alone Together: Craft Collectives And Guilds in the Digital Age}

We now live in a world in which technology and digital devices dominate our modes of communication and production. The internet is a game changer for craftspeople and designer makers in Australia, disruptive for the better in a classic long tail way (Anderson 2007). Research elsewhere, most notably in the UK (Harvey et al. 2011, 2012; Hawkins et al.2009; Thomas 2018), has identified the important historical and ongoing role of guilds, training organisations, artists' collectives (including retail outlets) and other collective organisations in supporting and resourcing creative micro-producers. This study coincided with a time of profound cutbacks to arts and cultural funding, especially at the national level. These cutbacks come on top of earlier years of declining funding for many parts of the sector under a conservative federal government. In contrast, the policy rhetoric and economic rationalism from both sides of politics has embraced the creative industries agenda, seeking to force those parts of the arts sector that can survive (but not necessarily thrive) in such an environment onto a more entrepreneurial footing:

Government action, in the creative industries model, is aimed at stimulating and liberating the latent, or untutored, entrepreneurial energies that lie in reserve in every pocket of cultural activity; a hand up, in other words, rather than a handout. (Ross 2007, 26)

Although little critical scholarship on the cultural and creative industries has focused on craft, it is notable that in this piece he singles out the historical collective power of this particular sector: 'the traditional cultural industries have been a relatively significant union stronghold with a long and fruitful history of mutual support between craft-based locals' (Ross $2007,20)$. This, he suggests, could be why conservative governments 
might be keen to dismantle collective support structures for artists and craftspeople.

Although it is almost guaranteed that Ross did not have the 'new world' context of contemporary Australia's craft industry associations in mind when making this statement, (more likely the guilds of Europe), at the state and territory, if not the national level, in Australia, an important range of collective organisations continue to support local makers in various ways. Their evolution and survival has been in response to the ebb and flow of various state and national reviews and reports into the arts and, more specifically, the craft sector. The influence of these shifts in policy and funding paradigms was reflected within the discussions with our established makers. Although there is no longer a national body to represent organisations and individual makers in the craft and design sector and advocate on their behalf, and despite shrinking funding in real terms, the peak organisations training, supporting, promoting and advocating on behalf of the sector have endured. This can be attributed partly to a collective voice and sharing experience through the Australian Craft and Design Centres (ACDC) network, as well as the Australian branch of the World Crafts Council (https://wccaustralia.org.au/) and the National Craft Initiative (a three-year partnership between the ACDC network and National Association for the Visual Arts (NAVA) (Hutchison 2016). Some of the ACDC member organisations ${ }^{3}$ remain strongly member-driven and collectivised, offering services such as affordable insurance, marketing and promotion, as well as advice sessions and support, each of which our interviewees identified as key reasons they value their membership. Some of the traditionally craft-focused associations have retained a strong and proud craft focus, while others have felt the need to diversify their membership base to include those who identify as visual artists or designers. In most instances, the organisations themselves identified as significant challenges servicing members spread over diverse disciplinary domains and often large geographical areas. Digital technology is obviously an important tool here, but if information, support and community are being accessed online, there is also a whole world of possibility out there beyond one's own state or territory. Regional, rural and remote makers singled out YouTube as a valuable resource for finding new making skills and helping with problem-solving (including social media and marketing issues), overcoming some of the negatives of being geographically located away from the offices of support organisations and other makers. 
This said, as we have stated elsewhere in this book, geography does still matter. As does face-to-face community. As we have also seen, histories of making in particular places ${ }^{4}$ have given rise to and sustained rich community ecosystems of making, such as furniture making in Tasmania and glass (and high-end craft generally) in Adelaide, thanks largely to almost 50 years of the JamFactory in that city (Fig. 8.7):

It's much deeper than that. So in fact [there is a physical series of interlinked spaces that] provides the hub, and all of this sort of old-fashioned social networking that happens around that hub is what builds a really strong and resilient community of practitioners. So Adelaide boasts one of the strongest and most resilient glass fraternities in the world because to some extent of that hub. I think it's the combination of the University of South Australia's School [of Art with its glassblowing courses] and the fact that a number of other people have chosen to reside here as [professional makers] who have nothing to do with the facility. [...] And all those things come out of the history that those two main centres have. So that enriches the [JamFactory] training programme, so the associates in the glass studio get to assist, work with, watch, talk to, learn from 50 regular glass blowers, many of whom are globally significant figures. (Brian Parkes, CEO of JamFactory, April 2015)

Individual artist-run initiatives, too, have long provided a supporting community for Australian craftspeople and designer makers, including some iconic ones such as Gray Street studio (jewellery and metal), Blue Pony (glass) and Jamboree Clay Workshop (ceramics), but many, unfortunately, are no longer in operation. This support is itself generally highly bespoke and personal and can take many forms, including a valuable and supportive family-friendly working environment for women makerssomething that is nearly impossible to replicate online:

And I called them up and I said, "have you got a space there?", and they were using that room as storage so they cleared it out for me and it was great. So my first year with [my daughter] she came with me. She was such a good little trooper that kid. Oh awesome. She'd sleep through hammering and the machines $[\ldots]$ So the studio was half nursery, half studio and, all the girls that worked there were like aunties to $[$ her]. [...] it was a great year. Last year was great and I had a huge-it was probably the best year of making I've ever had and it was-lots of ideas had been bubbling around which I couldn't get to just happened. (Kath Inglis, jewellery, established maker, October 2015) 


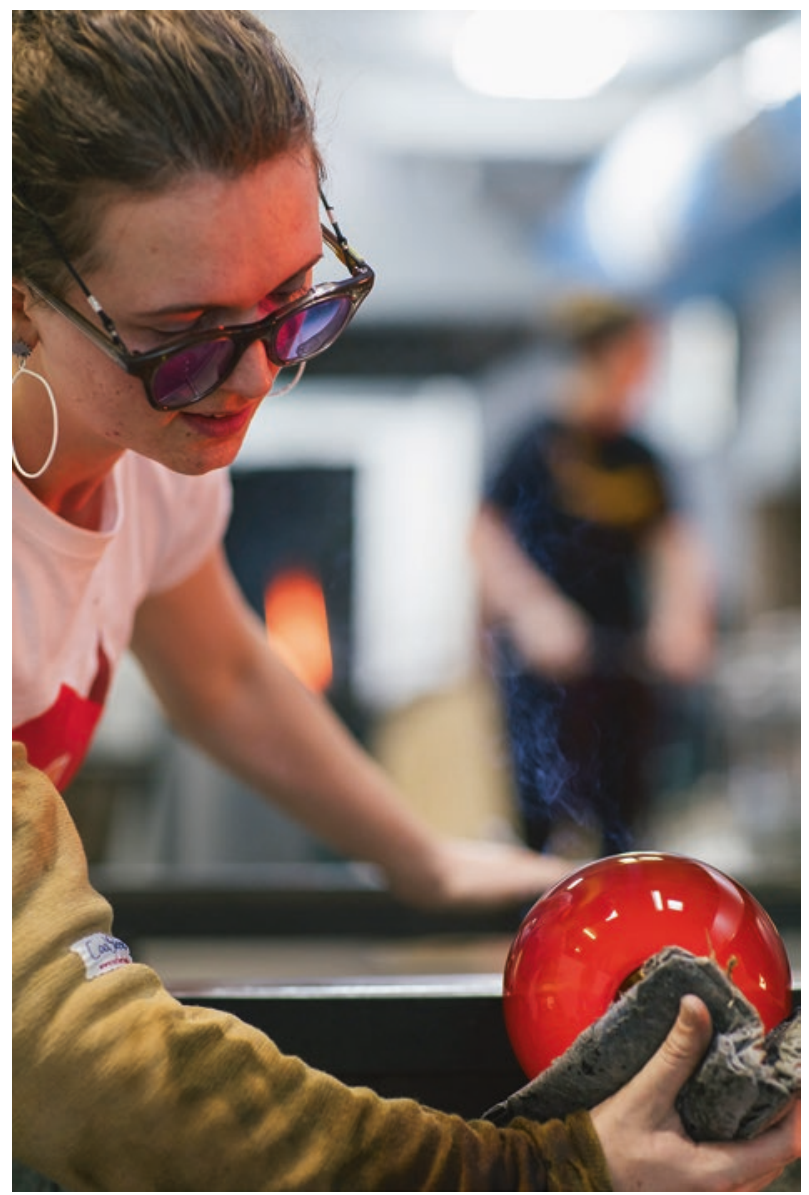

Fig. 8.7 Emma Young blowing glass at the JamFactory. (Photograph: Rosina Possingham Photography)

Well you see my daughter she used to come in to Workshop 3000 and she used to sit in the little playpen in the workshop and, yeah, she was a constant in the room. (Marian Hosking, jewellery, established maker, October 2015)

We found that many contemporary creative makers who were sole traders still chose to join others working in the same market. This gave them 
the benefits of a collective: enabling them to access and share knowledge; collectively market their businesses; and advocate for services, financial support and resources that they were unable to access individually. New forms of public and private co-working spaces are emerging, providing a rich local ecology within which to work. Both off- and online, we were struck by the visible levels of mutual support and friendliness permeating the maker community, at least in public. There will always be antagonisms, personal histories and jealousies, but overall (while acknowledging the concerns expressed in the previous section about 'fit'), we found a highly friendly community that believed that all makers benefit from a lively, active craft and design sector, one with customers keen to choose local handmade goods over cheaper, industrially produced goods from overseas. This study may have coincided with a particular moment of peaking interest in craft, the handmade and the artisanal, but revealed within the deep histories of making presented here, both personal and collectively grounded in place, is the ongoing affective power of making. As we have written, Bennett (2001) writes of the 'enchantment' that is to be found in both doing it and purchasing into its world of values: 'I locate the enchantment effect primarily in the aesthetic or theatrical dimension of commodities and in the way that commodities function as tangible and public elaborations of, and experimentations with, personal and collective identities' (114). This role for craft and designer making is likely to become even more important as we, as privileged citizens of the Global North (such as most of the Australian population), find ourselves needing to make profound changes to how we live, including how we engage with the material world around us, in the face of climate change. We take heart from and agree with leading British craft writer and thinker Rosy Greenlees (2016) when she writes:

The fact of the matter is that those working around the fringes of craft may come and go. The current vogue for calling all things 'craft' will wane undoubtedly. But craft is a way of life and something well beyond glib fashion. Rather than worrying ourselves around linguistics, it seems to me that these are exciting times for craft. There's a new sense of its possibilities and how its processes can extend beyond making beautiful objects and life meaningful, and move into areas such as technology, medicine and industry. By doing so, there is a developing comprehension that skill and a deep understanding of materials can help solve real problems. The truth of the matter is that we are surrounded by craft, and craft is here to stay. (97) 
This study reveals that despite government funding cutbacks and the winding back of actual hands-on making skills development in higher education, for the time being at least, Australia's craft and designer maker sector is a strong and growing one. Moving forward, several challenges remain. Among these is to ensure, strategically and sustainably, the ability to transfer practical making skills across generations to new makers. It is critical that, in collaboration with both one another and other communities of knowledge and practice, the country's makers play their own essential role in addressing the wicked challenges of the future.

\section{Notes}

1. See Morgan and Nelligan $(2018,2015)$ for a detailed discussion of how class and gender impact upon the career aspirations and chances of success (in the form of sustainable employment) in Australia's creative industries.

2. The relative racial homogeneity of much of the Australian making community is a concerning example of this. Certainly, in her research into the experiences of Black, Asian and Minority Ethnic (BAME) makers in the UK for the Crafts Council, Karen Patel has found that access to social media, not only in terms of actual skills but also, notably, concerns over the safety of making themselves visible in the ways required, was a significant barrier to BAME makers' involvement in online and, from there, face-to-face craft communities (Patel 2019).

3. ACDC members are Artisan (QLD), Australian Design Centre (NSW), Australian Tapestry Workshop (VIC), Canberra Glassworks (ACT), Central Craft (NT), Craft (VIC), Craft ACT (ACT), Design Tasmania (TAS), Form (WA), Guildhouse (SA), JamFactory (SA) and Sturt Gallery and Studios (NSW).

4. In a post-colonisation context, this experience mirrors the findings of British studies undertaken by scholars at King's College, London (Comunian and England 2018a, b).

\section{REFERENCES}

Adkins, L., \& Lury, C. (1999). The labour of identity: Performing identities, performing economies. Economy and Society, 28(4), 598-614.

Anderson, C. (2007). The long tail: How endless choice is creating unlimited demand. London: Random House.

Banks, M., \& Oakley, K. (2016). The dance goes on forever?: Art schools, class and UK higher education. International Journal of Cultural Policy, 22(1), 41-57. 
Bennett, J. (2001). The enchantment of modern life: Attachments, crossings, and ethics. Princeton and Oxford: Princeton University Press.

Comunian, R., \& England, L. (2018a). The resilience of knowledge from industrial to creative clusters: The case of regional craft clusters in the West Midlands (UK). In T. Baycan \& H. Pinto (Eds.), Resilience, crisis and innovation dynamics (pp. 326-346). Cheltenham, UK and Northampton, MA: Edward Elgar Publishing.

Comunian, R., \& England, L. (2018b). Creative clusters and the evolution of knowledge and skills: From industrial to creative glassmaking. Geoforum, $99,238-247$.

Conor, B. (2014). Screenwriting: Creative labor and professional practice. London: Routledge.

Conor, B., Gill, R., \& Taylor, S. (2015). Gender and creative labour. In B. Conor, R. Gill, \& S. Taylor (Eds.), Gender and creative labour (Sociological Review Monograph Series, 63, S1) (pp. 1-22). Chichester: Wiley Blackwell/The Sociological Review.

Deuze, M. (2007). Media work. Cambridge and Malden: Polity Press.

Duffy, B. E., \& Pruchniewska, U. (2017). 'Having it all' on social media: Entrepreneurial femininity and self-branding among fashion bloggers. Social Media + Society, 1, 1-11.

Duffy, B. E. (2015). Amateur, autonomous, and collaborative: Myths of aspiring female cultural producers in Web 2.0. Critical Studies in Media Communication, $32,48-64$.

Duffy, B. E. (2016). The romance of work: Gender and aspirational labour in the digital culture industries. International Journal of Cultural Studies, $19,441-457$.

Duffy, B. E. (2017). (Not) Getting paid to do what you love: Gender, social media, and aspirational work. New Haven and London: Yale University Press.

Ekinsmyth, C. (2012). Family friendly entrepreneurship: New business formation in family spaces. Urbani izziv, 23(1), S115-S125.

Ekinsmyth, C. (2013). Managing the business of everyday life: The roles of space and place in 'mumpreneurship'. International Journal of Entrepreneurial Behaviour and Research, 19(5), 525-546.

Gill, R., \& Pratt, A. (2008). In the social factory?: Immaterial labour, precariousness and cultural Work. Theory, Culture Er Society, 25(7-8), 1-30.

Greenlees, R. (2016). Learning through culture. Crafts, March-April, p. 97.

Harvey, D., Hawkins, H., \& Thomas, N. (2012). Thinking creative clusters beyond the city: People, places and networks. Geoforum, 43(3), 529-539.

Harvey, D., Hawkins, H., \& Thomas, N. J. (2011). Regional imaginaries of governance agencies: Practising the region of South West Britain. Environment and Planning A: Economy and Space, 43(2), 470-486. 
Hawkins, H., Harvey, D., \& Thomas, N. (2009). Creating the region: Networking the region. Regional Studies, 47(1), 75-88.

Hearn, A. (2008). Meat, mask, burden: Probing the contours of the branded 'self'. Journal of Consumer Culture, 8(2), 197-217.

Humphreys, L., \& Wilken, R. (2015). Social media, small businesses, and the control of information. Information, Communication and Society, $18(3), 295-309$.

Hutchison, G. (2016). Agenda for Australian craft and design. Canberra: NAVA and National Craft Initiative.

Kuehn, K., \& Corrigan, T. F. (2013). Hope labor: The role of employment prospects in online social production. Political Economy of Communication, $1(1), 9-25$.

Luckman, S. (2015). Craft and the creative economy. London and New York: Palgrave Macmillan.

Luckman, S. (2020). 'Craftsperson', 'artist', 'designer': Problematising the 'art versus commerce' divide within Australian creative fields today. In D. Stevenson, T. Bennett, F. Myers, \& T. Winikoff (Eds.), The Australian art field: Frictions and futures. Routledge.

Mäkinen, K. (2018). Negotiating the intimate and the professional in mom blogging. In S. Taylor \& S. Luckman (Eds.), The new normal of working lives: Critical studies in contemporary work and employment (pp. 129-146). Cham, Switzerland: Palgrave Macmillan.

Morgan, G., \& Nelligan, P. (2015). Labile labour-Gender, flexibility and creative work. In B. Conor, R. Gill, \& S. Taylor (Eds.), Gender and creative labour (pp. 66-83). Chichester: John Wiley \& Sons.

Morgan, G., \& Nelligan, P. (2018). The creativity hoax: Precarious work in the gig economy. London: Anthem Press..

Moss-Racusin, C., \& Rudman, L. (2010). Disruptions in women's self-promotion: The backlash avoidance model. Psychology of Women Quarterly, 34(2), 186-202.

Naudin, A., \& Patel, K. (2019). Entangled expertise: Women's use of social media in cultural work. European Journal of Cultural Studies, 22(5-6), 511-527. (First published electronically 19 December 2017.).

Neff, G., Wissinger, E., \& Zukin, S. (2005). Entrepreneurial labor among cultural producers: "Cool" jobs in "hot" industries. Social Semiotics, 15(3), 307-328.

Patel, K. (2019, February). Supporting diversity in craft practice through digital skills development: Project report. London: Crafts Council. Retrieved February 4, 2020, fromhttps://www.craftscouncil.org.uk/downloads/ supporting-diversity-in-craft-practice-report/

Ross, A. (2007). Nice work if you can get it: The mercurial career of creative industries policy. In G. Geert \& N. Rossiter (Eds.), My creativity reader: A critique of creative industries (pp. 19-41). Amsterdam: Institute of Network Cultures. 
Taylor, S. (2011). Negotiating oppositions and uncertainties: Gendered conflicts in creative identity work. Feminism \& Psychology, 21, 354-371.

Taylor, S., \& Littleton, K. (2016). Contemporary identities of creativity and creative work. London and New York: Routledge.

Thomas, N. J. (2018). Modernity, crafts and guilded practices: Locating the historical geographies of 20th century craft organisations. In L. Price \& H. Hawkins (Eds.), Geographies of making, craft and creativity (pp. 60-77). Abingdon, Oxon and New York: Routledge.

Vivienne, S., \& Burgess, J. (2012). The digital storyteller's stage: Queer everyday activists negotiating privacy and publicness. Journal of Broadcasting \& Electronic Media, 56(3), 362-377.

Open Access This chapter is licensed under the terms of the Creative Commons Attribution 4.0 International License (http://creativecommons.org/licenses/ by $/ 4.0 /$ ), which permits use, sharing, adaptation, distribution and reproduction in any medium or format, as long as you give appropriate credit to the original author(s) and the source, provide a link to the Creative Commons licence and indicate if changes were made.

The images or other third party material in this chapter are included in the chapter's Creative Commons licence, unless indicated otherwise in a credit line to the material. If material is not included in the chapter's Creative Commons licence and your intended use is not permitted by statutory regulation or exceeds the permitted use, you will need to obtain permission directly from the copyright holder.

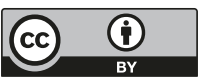

